\title{
Papers
}

\section{Violations of the international code of marketing of breast milk substitutes: prevalence in four countries}

\author{
Anna Taylor
}

\begin{abstract}
Objective: To estimate the prevalence of violations of the international code of marketing of substitutes for breast milk in one city in each of Bangladesh, Poland, South Africa, and Thailand.

Design: Multistage random sampling was used to select pregnant women and mothers of infants $\leqslant 6$ months old to interview at health facilities. Women were asked whether they had received free samples of substitutes for breast milk (including infant formula designed to meet the nutritional needs of infants from birth to 4 to 6 months of age, follow on formula designed to replace infant formula at the age of 4 to 6 months, and complementary foods for infants aged $\leqslant 6$ months), bottles, or teats. The source of the free sample and when it had been given to the women was also determined. 3 health workers were interviewed at each facility to assess whether the facility had received free samples, to determine how they had been used, and to determine whether gifts had been given to health workers by companies that manufactured or distributed breast milk substitutes. Compliance with the marketing code for information given to health workers was evaluated using a checklist.

Setting: Health facilities in Dhaka, Bangladesh; Warsaw, Poland; Durban, South Africa; and Bangkok, Thailand.

Subjects: 1468 pregnant women, 1582 mothers of infants aged $\leqslant 6$ months, and 466 health workers at 165 health facilities.
\end{abstract}

Main outcome measures: Number of free samples received by pregnant women, mothers, and health workers; number of gifts given to health workers; and availability of information that violated the code in health facilities.

Results: 97 out of $370(26 \%)$ mothers in Bangkok reported receiving free samples of breast milk substitutes, infant formula, bottles, or teats compared with only 1 out of 385 mothers in Dhaka. Across the four cities from 3 out of $40(8 \%)$ to 20 out of $40(50 \%)$ health facilities had received free samples which were not being used for research or professional evaluation; from 2 out of 123 (2\%) to 21 out of 119 $(18 \%)$ health workers had received gifts from companies involved in the manufacturing or distribution of breast milk substitutes. From 6 out of $40(15 \%)$ to 22 out of $39(56 \%)$ health facilities information that violated the code had been provided by companies and was available to staff.

Conclusion: Violations of the code were detected with a simple survey instrument in all of the four countries studied. Governmental and non-governmental agencies should monitor the prevalence of code violations using the simple methodology developed for this study.

\section{Introduction}

The World Health Organisation estimates that 1.5 million babies could be prevented from dying each year if women breast fed their infants (exclusively for about 6 months and until infants were 2 years old). ${ }^{1}$ Where a mother uses an alternative to breast milk to feed her baby, it is important that she makes an informed decision and that she has not been pressured by commercial promotions to use a substitute. The international code of marketing of breast milk substitutes $^{2}$ was adopted by the World Health Assembly in 1981 to encourage breast feeding and to protect mothers from pressure to use substitutes for breast milk. At that time one member state (the United States) voted against the code and three abstained (Argentina, Japan, and Korea); by the 1996 World Health Assembly meeting all 191 member states had affirmed their support for the code, its implementation, and the implementation of relevant resolutions. By 1997, 17 countries had adopted all or substantially all of the code's provisions as legal requirements. ${ }^{3}$ Adoption of the code represents the development of an international consensus.

Anecdotal evidence of violations of the code has been presented but no previous studies have used formal sampling techniques. ${ }^{4}$ This study was designed to measure the prevalence of violations of the code using randomly sampled groups of women, health workers, and health facilities in four cities.

The study was overseen and supported financially or by other means by 27 churches, academic institutions, and international non-governmental organisations. Experts in infant feeding were contacted for advice. Accommodation was provided by Unicef United Kingdom. The organisations and people who chose to participate wanted to obtain unbiased information on violations of the marketing code. No funding, support, or advice was received from the manufacturers of breast milk substitutes or

\section{Editorial by Costello and Sachdev \\ Interagency Group on Breastfeeding Monitoring, Unicef United Kingdom \\ Committee, \\ London \\ WC2A 3NB \\ Anna Taylor, research coordinator \\ Correspondence to: Anna Taylor}

BMJ 1998;316:1117-22

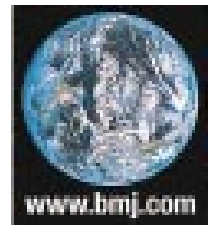

Additional information is available on the internet 
organisations forming part of the International Baby Food Action Network (Penang, Malaysia).

\section{Subjects and methods}

\section{Sampling procedure}

Since no studies of this kind had been done before a $10 \%$ prevalence of reported violations was assumed to be an important amount of violation. A sample of 800 women would give a $95 \%$ power to observe at least one reported violation if the true prevalence was $2 \%$. If the prevalence was $10 \%$ the sample size would generate estimates of population prevalence with a standard error of $1 \%$. Sample sizes for health workers and health facilities were constrained by practical considerations.

\section{Selection of countries}

Countries were grouped into three categories that reflected the status of requirements for compliance with the marketing code. In 63 countries compliance with the code was a legal requirement; in 36 countries compliance with the code was voluntary; and in 96 countries the code had another status, including no code, code awaiting government approval, or the status was unknown. ${ }^{3}$ A small subset of countries where there were agencies already working in partnership with the Interagency Group on Breastfeeding Monitoring were selected in each category to participate in preliminary discussions on the feasibility of the study (3 of the 63 countries in which compliance was legally mandatory, 2 of the 36 in which compliance was voluntary, and 5 of the 96 classed as giving the code any other status). These countries had contrasting geographical and

\section{Extracts from the international code of marketing of breast milk} substitutes $^{2}$

\section{Article 2 (products covered by the code)}

The code applies to the marketing, and practices related thereto, of the following products: breast milk substitutes, including infant formula; other milk products; foods and beverages, including bottle fed complementary foods, when marketed or otherwise represented to be suitable, with or without modification, for use as a partial or total replacement of breast milk; feeding bottles; and teats. It also applies to their quality and availability, and to information concerning their use

Article 5.2 (provision of samples)

Manufacturers and distributors should not provide, directly or indirectly, to pregnant women, mothers, or members of their families, samples of products within the scope of this code.

Article 7.2 (provision of information to health workers)

Information provided by manufacturers and distributors to health professionals regarding products in the scope of this code should be restricted to scientific and factual matters and such information should not imply or create a belief that bottle feeding is equivalent or superior to breast feeding. It should also include the information specified in article 4.2.

\section{Article 7.3 (provision of inducements to health workers)}

No financial or material inducements to promote products within the scope of this code should be offered by manufacturers or distributors to health workers or members of their families.

\section{Article 7.4 (provision of samples to health workers)}

Samples of infant formula or other products within the scope of this code ... should not be provided for health workers except when necessary for the purpose of professional evaluation or research at the institutional level. Health workers should not give samples of infant formula to pregnant women, mothers of infants and young children, or members of their families. economic conditions. After discussions with partner agencies six countries were excluded from the study because government permission or personnel support could not be secured.

The final four countries selected were Bangladesh (where compliance with the code is a legal requirement), Poland (which has no code), South Africa (where compliance is voluntary), and Thailand (where compliance is voluntary).

Cities-The capital city was chosen for the study in each country; however, in South Africa, government authorities suggested that the study should be done in Durban because the University of Natal would be able to manage the study.

Districts-Seventeen districts in Warsaw and 23 in Bangkok in which there were at least four health facilities that served pregnant women and mothers of infants were identified and numbered serially; 10 districts were selected using random numbers. In Dhaka 17 districts which had a minimum of four health facilities and in which $20 \%$ of the people were living slums were selected to reflect the overall proportion of people living in slums in the city. Districts were numbered and 10 were selected using random numbers. In Durban there were 93 districts but there were not enough facilities in each district for the same selection procedure to be followed. To ensure a large enough sample of health facilities 23 districts were randomly selected.

Health facilities-To be considered eligible for sampling health facilities had to be large enough to see daily at least 10 pregnant women or mothers of infants who were $\leqslant 6$ months old. Altogether 132 facilities met the inclusion criteria in Warsaw, and 159 met the criteria in Bangkok. All facilities that met the criteria in the 10 districts were numbered, and four were selected from each district using random numbers; thus, 40 health facilities were studied in each of these cities. In Dhaka 40 facilities met the inclusion criteria and in Durban 46 met the criteria; all of these facilities were included in the study. The coordinators in each country and the interviewers had had no prior contact with staff or mothers at the health facilities studied.

\section{Definitions}

All products marketed for infants younger than 6 months and all follow on formulas were considered to be breast milk substitutes. Infant formulas are those substitutes designed to be used from birth up to 4 to 6 months of age. Follow on formulas are designed to replace infant formulas at the age of 4 to 6 months. These definitions were based on World Health Assembly resolution 47.5 (1994) which clarified the code and recommended "fostering appropriate complementary feeding practices from the age of about six months." World Health Assembly resolutions passed after the code was adopted in 1981 have the same status as the code, which was adopted as part of World Health Assembly resolution 34.22. Article 2 of the code specifies the products covered by the code.

A gift was considered to be any item, except that which is defined as a product in the code, given to a health worker by a company that manufactures or distributes breast milk substitutes. 


\section{Subjects}

Over two days 20 pregnant women or mothers of infants aged $\leqslant 6$ months were selected from the appointment register at each facility and interviewed. Where no appointment register was available women were systematically sampled according to their position in the waiting room (for example, every fifth consecutive woman was selected). During the same two days, three health workers at each facility were interviewed. The selection of health workers depended on their availability for interview. Interviews with staff at different levels of seniority were sought. Wherever possible confidential interviews were carried out in a quiet designated area. A target sample size of 800 women and 120 health workers was set for each city, except Dhaka where there were problems with transportation because of the rainy season.

\section{Interview procedure}

The research coordinator (AT) trained 10 people in each country to interview pregnant women, mothers, and health workers using structured questionnaires; they were also trained to use a checklist to assess materials produced by companies that manufactured breast milk substitutes. (A copy of the checklist can be found on our website at www.bmj.com.) All data were collected within each country during one month between August and October 1996.

Country coordinators came from a variety of different backgrounds. In Dhaka the coordinator was a health visitor. In Durban the coordinator was an epidemiologist. In Bangkok the network director of a non-governmental organisation acted as coordinator and in Warsaw a doctor specialising in lactation management coordinated the study. Interviewers also came from a variety of backgrounds. In Dhaka interviewers had previous experience of similar work and were selected by interview. In Durban interviewers came from the university's faculty of medicine. In Bangkok professional market researchers collected the data, and in Warsaw postgraduate students from various disciplines collected the data.

As a result of a field test in Poland the format of the questionnaire was modified to make it easier to complete. In each country coded questionnaires were translated from English to the local language; in order to exclude linguistic errors they were then translated back by an independent translator. Interviews were confidential and responses anonymised. The number of people who declined to participate was recorded.

Pregnant women and mothers were asked if they had been given free samples of a breast milk substitute, feeding bottle, or teat. If they had, they were asked when and from whom it had been received. Health workers were asked whether they or the facility in which they worked had received any free samples and for what purpose they had been used. They were asked whether they had received any gifts from companies that manufactured products covered by the code and whether the gift had carried the brand name of a product.

Validation procedure-To confirm the validity of women's responses, $20 \%$ of the mothers in each city who had reported receiving free samples were asked about the samples and where they had received them. The details were recorded and then staff at the facility that had provided the sample were interviewed. Staff were asked about the availability of samples and their responses were compared with the woman's report.

Assessment of written information-Health workers were asked to show the interviewer the materials that had been provided for professional use by manufacturers. These materials were then assessed by the interviewer using a checklist based on the requirements of relevant articles of the code (4.2 and 7.2) (box).

Data management-The country coordinator was responsible for the quality of the data and supervision of the interviewers. In each country data were entered by a trained data clerk using EpiInfo software; data were analysed in London. Confidence intervals for proportions were estimated assuming a $\beta$ binomial random effects model to take account of possible variation between clinics. ${ }^{5}$

\section{Results}

\section{Health facilities and respondents}

Forty health facilities were visited in Dhaka, 46 in Durban, 40 in Bangkok, and 39 in Warsaw (one facility was closed for a holiday). In Dhaka 704 women were approached for an interview and all agreed to participate. In Warsaw 794 women were approached and three declined to participate. In Durban 804 women were approached; five declined to participate. In Bangkok 748 women were approached; 52 declined to participate. In Dhaka 112 health workers were asked to participate; one declined. In Warsaw 119 were approached and four declined. In Durban 123 were approached and one declined. In Bangkok 112 were approached and eight declined.

Many factors may have affected the mix of women attending the facilities in the samples. Some facilities were privately run, some were run by the state, and some were run by non-governmental organisations. Criteria for registration at specific facilities varied from residence in specific catchment area (Warsaw) to personal preference for private facilities (Bangkok). In Dhaka facilities were often small outpatient clinics where the number of patients seen was just enough to qualify for inclusion in the study, though large hospitals were also included in the sample. In Durban, attendance at a particular facility was usually limited to specific ethnic groups. Ease of access for researchers also varied between and within cities. A police escort was needed to visit some facilities in Durban. In Dhaka it was necessary to wade through deep water to reach some clinics. Most facilities in Warsaw and Bangkok were easily accessible.

\section{Free samples}

In Bangkok 97 out of 370 (26\%; 95\% confidence interval $18 \%$ to $36 \%$ ) mothers reported receiving free samples of a breast milk substitute, feeding bottle, or teat (table); many women received more than one sample. This was a greater proportion than that found in the other three cities. In Dhaka only one woman reported receiving a free sample. In all cities mothers were more likely than pregnant women to report having received free samples.

Health workers reported receiving free samples in as many as half of the facilities visited; none of the samples were being used for professional evaluation or 
Free samples and gifts received by pregnant women, mothers of infants $\leqslant 6$ months old, and health workers by city, type of sample received, and source of sample; and number of health facilities that received information from manufacturers that violated the international code of marketing of substitutes for breast milk

\begin{tabular}{|c|c|c|c|c|}
\hline Group or source & Dhaka & Warsaw & Durban & Bangkok \\
\hline \multicolumn{5}{|l|}{ Pregnant women } \\
\hline No (\%) receiving free sample & $0 / 319$ & $6 / 364(2)$ & $3 / 407(1)$ & $13 / 378(3)$ \\
\hline \multicolumn{5}{|l|}{ Type of free sample (No) ${ }^{\star}$ : } \\
\hline Infant formula & 0 & 0 & 1 & $15 \mathrm{~F}$ \\
\hline Feeding bottle or teat & 0 & 1 & 0 & 0 \\
\hline Other breast milk substitute $\dagger$ & 0 & 4 & 2 & 1 \\
\hline \multicolumn{5}{|l|}{ Mothers of infants $\leqslant 6$ months old } \\
\hline No (\%) receiving free samples & $1 / 385(0.3)$ & $34 / 430(8)$ & 13/397 (3) & $97 / 370(26)$ \\
\hline \multicolumn{5}{|l|}{ Type of free sample (No) ${ }^{\star}$ : } \\
\hline Infant formula & 0 & 1 & 6 & 95 \\
\hline Feeding bottle or teat & 0 & 7 & 4 & 55 \\
\hline Other breast milk substitute $\dagger$ & 1 & 28 & 3 & 2 \\
\hline \multicolumn{5}{|c|}{ Source of free samples (No) provided to pregnant women and mothers } \\
\hline Health facility & 0 & 24 & 14 & 152 \\
\hline Direct mail or retail & 1 & 6 & 0 & 17 \\
\hline \multicolumn{5}{|l|}{ Health workers } \\
\hline $\begin{array}{l}\text { No (\%) reporting free samples received at } \\
\text { health facility }\end{array}$ & $3 / 40(8)$ & $8 / 39(21)$ & $9 / 46(20)$ & $20 / 40(50)$ \\
\hline \multicolumn{5}{|l|}{ Type of free sample (No) ${ }^{*}$ : } \\
\hline Infant formula & 5 & 7 & 5 & 34 \\
\hline Feeding bottle or teat & 0 & 0 & 1 & 0 \\
\hline Other breast milk substitute $†$ & 0 & 4 & 6 & 0 \\
\hline $\begin{array}{l}\text { No (\%) of health workers who reported } \\
\text { receiving gifts }\end{array}$ & $19 / 112(17)$ & $21 / 119(18)$ & $2 / 123(2)$ & $9 / 112(8)$ \\
\hline $\begin{array}{l}\text { No (\%) of health facilities reported by } \\
\text { health workers to have received } \\
\text { information that violated the code }\end{array}$ & $6 / 40(15)$ & $22 / 39(56)$ & $8 / 46$ (17) & $13 / 40(33)$ \\
\hline
\end{tabular}

*Some women and health workers reported receiving more than one sample; in Warsaw one sample and in Bangkok two samples were of an unknown type and are not included in the table.

tOther breast milk substitutes include follow on formulas and complementary foods.

research at the institutional level as specified by article 7.4 of the code. The proportion of health facilities where staff reported receiving samples was highest in Bangkok (20/40) and lowest in Dhaka (3/40) (table).

The table shows that in each city except Dhaka the health service was the most common source of samples received by women. Only a small number were received by direct mail or from retail outlets. Of the samples that pregnant women and mothers reported receiving 118 out of $226(52 \%)$ were infant formula and 67 out of $226(30 \%)$ were bottles or teats (table). In Warsaw where other breast milk substitutes (complementary foods marketed for infants younger than 6 months and follow on formulas marketed for infants between 4 and 6 months old) contributed a greater proportion to the total number of samples received, 24 out of $32(75 \%)$ of samples were received before the infant was 4 months old. Overall, health workers reported receiving samples of infant formula more frequently than other samples; other breast milk substitutes were also received in Warsaw and Durban.

\section{Validation}

In Bangkok 97 out of 370 mothers reported receiving free samples. Eighteen of the 19 mothers in the validation subset described the samples they had received. The interviewer found that 12 samples were still available. One type of sample described was no longer available but the researcher was able to confirm that that type of sample had at previously been dispensed by the facility. No additional information could be obtained about the other five samples that mothers reported receiving. In Warsaw 34 mothers reported receiving free samples; some mothers received more than one sample. All seven mothers in the validation subset were contacted. Information was available about only three of the samples. In Dhaka the single reported free sample was not verified. Problems with transportation in Durban prevented us from verifying any of the 13 free samples reported.

\section{Information and gifts provided to health workers}

Health workers in 22 out of $39(56 \% ; 95 \%$ confidence interval $41 \%$ to $72 \%$ ) health facilities in Warsaw received information from manufacturers which violated the code. This was higher than in the other three cities where prevalence ranged from 6 out of 40 (15\%; $4 \%$ to $26 \%$ ) health facilities in Dhaka to 13 out of 40 (33\%; 18\% to 47\%) in Bangkok (figure).

Gifts donated by companies were received by 21 out of $119(18 \% ; 10 \%$ to $27 \%)$ health workers in Warsaw and 19 out of $112(17 \% ; 11 \%$ to $26 \%)$ health workers in Dhaka. Gifts were donated for personal use and included pens, notebooks, calendars, and tee shirts. Altogether 51 out of $70(73 \%)$ gifts were reported to carry the brand name of a product.

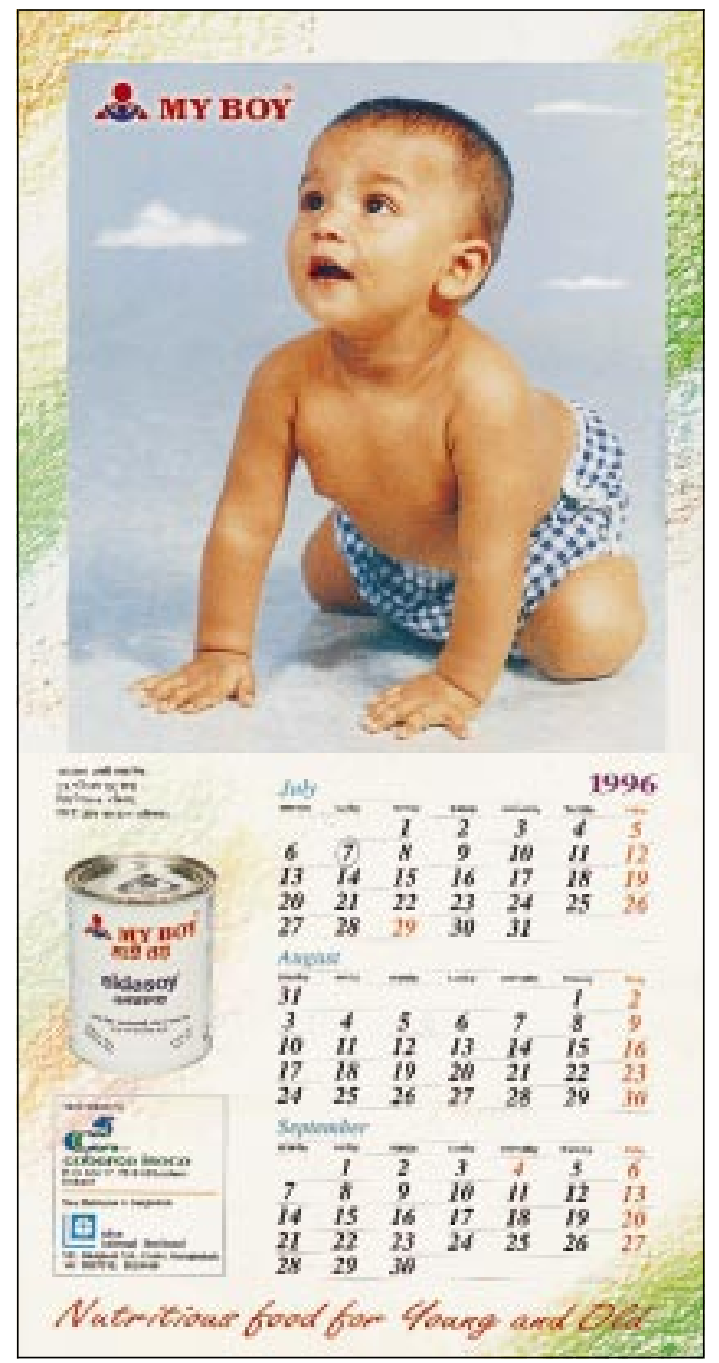

Calendar given to a health worker in Dhaka, Bangladesh. The code states that no material inducement to promote a product should be offered by manufacturers of breast milk substitutes to health workers 


\section{Discussion}

In this study pregnant women and mothers in four cities reported receiving free samples of infant formula, other breast milk substitutes, feeding bottles, or teats in contravention of articles 5.2 and 7.4 of the international code of marketing of substitutes for breast milk. None of the free samples were to be used for professional research purposes according to reports from health workers interviewed at the health facilities. The greater the number of facilities given samples in each city the greater the proportion of pregnant women and mothers who received samples. Most of the samples were reported to have come from a health facility; this suggests that samples given to facilities were passed on to mothers, whether or not that was the intention of the company donating the samples.

The effect of giving free samples of infant formula, bottles, and teats to women who are breast feeding has been examined in five studies. ${ }^{6-10}$ Frank et al reported that women receiving a discharge pack that contained products consistent with the code (such as breast pads and pamphlets on breast feeding) were more likely to breast feed for longer than those receiving a commercial discharge pack (containing formula, bottles, or teats), were more likely to be breast feeding at 4 months post partum, and were more likely to delay feeding solid foods. ${ }^{11}$ Two meta-analyses of the five studies confirmed that commercial discharge packs have a detrimental effect on breast feeding at one month after birth (odds ratios 1.45 (95\% confidence interval 1.07 to $1.96)^{12}$ and $\left.1.4(1.0 \text { to } 2.1)^{13}\right)$.

Article 7.3 of the code outlines the responsibilities of both health professionals and manufacturers as they pertain to the donation and receipt of gifts, yet widespread violations were detected in the four cities surveyed. Although many of the gifts were of little value financially, health professionals working in underfunded healthcare systems, such as in Bangladesh, may find it difficult to resist accepting these inducements. The presence of brand name items in the health facility may constitute professional endorsement of a particular product to patients seen in the facility.

The code states that all information produced by companies that manufacture or distribute breast milk substitutes must include details on the benefits and superiority of breast feeding and the risks associated with bottle feeding (articles 4.2 and 7.2). Nevertheless, $15 \%$ to $56 \%$ of health workers interviewed stated that their facilities had received materials that contravened these articles.

It may not be possible to generalise these findings to other areas because conditions in rural districts could be different. Equally, the promotional activities of companies may vary from country to country and city to city. However, both the number and nature of code violations suggest that systematic contravention of the code exists; it would be reasonable to believe that similar violations are occurring at similar rates in other cities and countries. These findings are the consequences of the promotional activities of 21 companies, six of which were trying to sell their products in more than one of the countries studied.
Key messages

- A simple multistage random sampling procedure can be used to interview women and health professionals to assess whether violations of the international code of marketing of substitutes for breast milk are occurring

- 3050 women and 466 health professionals were interviewed at 165 health facilities in Bangladesh, Poland, South Africa, and Thailand

- 97 out of 370 mothers in Bangkok reported receiving free samples of breast milk substitutes, infant formula, bottles, or teats compared with only 1 out of 385 mothers in Dhaka. In Bangkok health workers reported that 20 out of 40 health facilities had also received free samples. Most free samples were distributed by health facilities

- In Warsaw $56 \%$ of facilities surveyed were found to have information available for health workers that had been provided by manufacturers or distributors of breast milk substitutes in contravention of the code; $18 \%$ of health workers in Warsaw had received free gifts from manufacturers

\section{Importance of implementation and monitoring of the code}

Bangladesh was the only country studied which had laws governing the marketing of breast milk substitutes; the smallest number of free samples were detected there. Warsaw had the highest number of health facilities in which information that violated the code was available to health professionals. Warsaw also had the highest proportion of health professionals who received free gifts; Poland has no legal or voluntary code governing any aspects of marketing discussed in this paper. South Africa and Thailand have voluntary codes. In Thailand the voluntary code was revised in 1995 .

The frequency of the violations occurring in four major cities shows that 16 years after the World Health Assembly adopted the code, its requirements are still unmet. There is little to suggest that the situation would be different in many other countries; the code is not enforced in its entirety under current legislation in the United Kingdom and Europe. ${ }^{14}$ There is little hope that breast feeding will be protected from commercial pressure as envisioned by the World Health Assembly unless there is a commitment to enforce and monitor the code nationally.

Monitoring is intermittently conducted at sentinel sites in many countries by the International Baby Food Action Network but this is the first study to measure the prevalence of violations in a random sample of women and health professionals. The results provide a baseline for continued surveillance. The protocol used in this study can be applied within a short time and with few resources, making it suitable for use by governments seeking to protect the health of mothers and young infants. 
The Interagency Group on Breastfeeding Monitoring is a coalition of organisations and individuals established to monitor independently the marketing code.

Dr Anthony Williams and Professor Andrew Tomkins gave editorial assistance in the preparation of the manuscript. Dr Anthony Ades gave statistical advice.

Contributors: Claire Grose, Dr Magdalena Gugulska, Christine Lucas, and Saree Aongsomwang acted as country coordinators. Alison Maclaine analysed the data. Caroline Leveaux provided managerial support. AT designed and implemented the study, wrote the paper, and is guarantor for the study.

Funding or other support was given by: the Ajahma Charitable Trust, British Association of Community Child Health, British Medical Association, Baptist Union of Great Britain, Bishop of Coventry Charity Projects, Children's Aid Direct, Christian Aid, Church of England Board for Social Responsibility, Church of Scotland, International Child Health Group, Methodist Church, Mother's Union, Oxfam United Kingdom and Ireland, Save the Children Sweden, Save the Children United Kingdom, Tear Fund United Kingdom, Unicef Regional Office for Central and Eastern Europe/Commonwealth of Independent States, United Kingdom Committee for Unicef, United Reformed Church (Church and Society), Voluntary Service Overseas, World Council of Churches, World Health Organisation Regional Office for Europe, World Vision United Kingdom.

Conflict of interest: None.
1 World Health Organisation. Infant and young child nutrition. Geneva: WHO, 1993. (EB93/17.)

2 WHO. International code of marketing of breastmilk substitutes. Geneva: WHO, 1981.

3 Sokol E. The code handbook. Penang: International Code Documentation Centre, 1997.

4 Baby Milk Action. Breaking the rules. Cambridge: Baby Milk Action, 1994. 5 Collett D. Modelling binary data. London: Chapman and Hall, 1991.

Bergevin Y, Dougherty C, Kramer MS. Do infant formula samples shorten the duration of breastfeeding? Lancet 1983;i:1148-51.

7 Dungy C, Christensen-Szalanski J, Losch M, Russell D. Effect of discharge samples on duration of breastfeeding. Pediatrics 1992;90:233-7.

8 Evans CJ, Lyons NB, Killien MG. The effect of infant formula samples on breastfeeding practice. J Obstet Gynecol Neonatal Nurs 1986;15:401-5.

9 Feinstein JM, Berkelhamer JB, Gruszka ME, Wong CA, Carey AE. Factors related to early termination of breastfeeding in an urban population. Pediatrics 1986;78:210-5.

10 Frank DA, Wirtz JS, Sorenson JR, Heeren T. Commercial discharge packs and breastfeeding counselling: effects on infant feeding practices in a randomized trial. Pediatrics 1987;80:845-54.

11 Frank DA, Wirtz JS, Sorenson JR, Heeren T. Commercial discharge packs and breastfeeding counselling: effects on infant feeding practices in a randomized trial. Pediatrics 1987;80:845-54.

12 Inch S, Garforth S. Establishing and maintaining breastfeeding. In: Effective care in pregnancy and childbirth. Chalmers I, Enkin M, Keirse MJNC, eds. Oxford: Oxford University Press, 1988.

13 Pérez-Escamilla R, Pollitt E, Lönnerdal B, Dewey K. Infant feeding policies in maternity wards and their effect on breast-feeding success: an analytical overview. Am J Pub Health 1994;84 (1):89-97.

14 Infant formula and follow-on formula regulations, 1995. London: HMSO, 1995.

(Accepted 27 November 1997)
Steroid Research

Laboratory,

Institute of

Biomedicine,

PO Box 8, 00014

University of

Helsinki, Finland

Pekka Lähteenmäki,

director

Janne Suvisaari,

research assistant

City Maternity

Hospital,

Sofianlehdonkatu

5 A, 00610 Helsinki

Maija Haukkamaa,

chief physician

Susanna Sainio,

assistant physician

continued over

BMJ 1998;316:1122-6

\section{Abstract}

Objectives: To assess whether the levonorgestrel intrauterine system could provide a conservative alternative to hysterectomy in the treatment of excessive uterine bleeding.

Design: Open randomised multicentre study with two parallel groups: a levonorgestrel intrauterine system group and a control group.

Setting: Gynaecology departments of three hospitals in Finland.

Subjects: Fifty six women aged 33-49 years scheduled to undergo hysterectomy for treatment of excessive uterine bleeding.

Interventions: Women were randomised either to continue with their current medical treatment or to have a levonorgestrel intrauterine system inserted.

Main outcome measure: Proportion of women cancelling their decision to undergo hysterectomy. Results: At 6 months, $64.3 \%$ (95\% confidence interval 44.1 to $81.4 \%$ ) of the women in the levonorgestrel intrauterine system group and $14.3 \%$ (4.0 to $32.7 \%)$ in the control group had cancelled their decision to undergo hysterectomy $(\mathrm{P}<0.001)$.

Conclusions: The use of the levonorgestrel intrauterine system is a good conservative alternative to hysterectomy in the treatment of menorrhagia and should be considered before hysterectomy or other invasive treatments.

\section{Introduction}

Menorrhagia is a major reason for hysterectomy among fertile women. ${ }^{1}$ Abnormal uterine bleeding is a common reason for consulting general practitioners. ${ }^{2}$ Until recently, medical treatment has been disappointing, ${ }^{3}{ }^{4}$ and various surgical alternatives in the form of endometrial ablation have been developed. ${ }^{5-7}$ The role of these surgical alternatives in the treatment of menorrhagia is not currently clear.

The progestin levonorgestrel, released from an intrauterine system at a rate of $20 \mu \mathrm{g} / 24$ hours, suppresses endometrial growth. The glands of the endometrium become atrophic and the epithelium inactive. ${ }^{9}$ This system, originally developed for contraception, ${ }^{10}{ }^{11}$ has been shown to decrease the amount and duration of normal menstrual flow. ${ }^{12}$ The results of a non-comparative study showed a reduction of menstrual blood loss of $86 \%$ in menorrhagic women in only 3 months and a further reduction to $97 \% 12$ months after insertion of the device. ${ }^{13}$ Comparison of the levonorgestrel intrauterine system with the non-steroidal anti-inflammatory drug flurbiprofen and tranexamic acid showed that the device decreased the measured volume of menstrual blood loss in comparison with control cycle measurements by $82 \%$ at 3 months and by $96 \%$ at 12 months, while the flurbiprofen and tranexamic acid treatments decreased menstrual blood loss by only $21 \%$ and $44 \%$, respectively. ${ }^{14}$ 